\title{
¿CONVIENE CONTINUAR CON LA APERTURA ECONÓMICA?
}

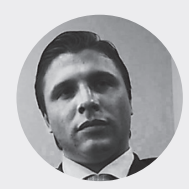

\author{
ANDRÉS M. REMEZZANO \\ - Profesor de Economía Empresarial \\ Carrera de Administración y Finanzas \\ Facultad de Negocios, UPC
}

No cabe duda que vivimos en un mundo cada vez más globalizado. Todos los días 40,000 personas viajan por aire entre Estados Unidos y Asia y un número similar lo hace entre estados Unidos y Europa. Cuando Nike produce más calzado deportivo para deportistas alrededor del mundo, los habitantes de China, indonesia y Malasia tienen más trabajo. Cuando Apple diseña un nuevo celular, las fábricas de China, Japón, Corea y Taiwán producen y ensamblan partes. Todo este proceso se retroalimenta todos los días y es producto de la especialización.

\section{¿POR QUÉ SE ESPECIALIZAN LOS PAÍSES?}

La teoría económica nos enseña algunos principios importantes para abordar esta interrogante. Ellos son el "costo de oportunidad" y la "ventaja comparativa". El costo de oportunidad es la alternativa de mayor valor a la que renunciamos para obtener algo. Por ejemplo, si decido estudiar una maestría a tiempo completo, mi costo de oportunidad puede ser el salario que dejaré de percibir al dejar, como consecuencia, de trabajar. Por otra parte, se dice que una persona o un país tienen una ventaja comparativa en una actividad si puede realizarla con un costo de oportunidad menor que el resto. Por ejemplo, Japón por muchos años tenía una ventaja comparativa en la producción de tecnología y Silicon Valley, California, tiene una ventaja comparativa en la producción de empresas y proyectos de internet y tecnología.

Estos dos conceptos fueron desarrollados por David Ricardo (1817) para construir una teoría alrededor del comercio. Para Ricardo, los países deben dedicarse a producir aquellos bienes y servicios en los cuales tienen una ventaja comparativa y exportarlos; e importar aquellos productos que no se producen localmente de países que tienen ventaja comparativa en producirlos. El resultado es que los países se dedican a producir lo que mejor hacen y el resto lo importan. Esto les permite alcanzar un mayor nivel de consumo que si no comerciaran y se dedicaran a tratar de producir todos los bienes que deberían importar. La especialización en la producción y el posterior comercio permite lograr un mayor consumo y así un mayor estándar de vida. Esto ocurre ya que se asignan los recursos de una manera más eficiente entre los países que comercian. Cada país logra producir más de los bienes en los cuales tiene ventaja comparativa. Ello tiene como resultado un mayor nivel de producción en el agregado entre los países que comercian entre sí y por consiguiente una mayor posibilidad de consumo luego del comercio.

\section{LA ESPECIALIZACIÓN EN LA PRODUCCIÓN Y EL POSTERIOR COMERCIO PERMITE LOGRAR UN MAYOR CONSUMO Y ASÍ UN MAYOR ESTÁNDAR DE VIDA.}

Entre las décadas del cincuenta y de los años sesenta, sin embargo, una mayoría de países adoptaron posturas proteccionistas respecto del comercio. En muchos casos, ello obedeció a la amenaza inminente a las industrias locales por parte de los bienes importados. Afortunadamente, ese afán proteccionista retrocedió en las décadas del 80 y del 90; en los últimos años el comercio mundial ha ido creciendo y casi todos los países han iniciado un proceso de apertura económica. El Perú no ha sido ajeno a este vaivén comercial. Así como el Perú en los años sesenta y setenta cometió el error de sustituir importaciones en el nombre del interés nacional, también se ha embarcado desde los años noventa en un proceso de apertura económica. Perú es hoy una economía inclusive más abierta que una década atrás. ¿Cómo podemos medirlo?

Una forma interesante de medir el nivel de apertura de un país es utilizar como indicador la suma de sus exportaciones e importaciones como proporción del producto bruto interno (PBI). Para ver lo que ha pasado en el Perú en los últimos años construimos el grafico 1, que muestra cómo ha evolucionado este indicador de apertura a lo largo de los años. Los datos utilizados se obtuvieron de la Penn World Table, que contiene información de más de 50 años y más de 150 países. Esta tabla es rica en la información que proporciona, ya que permite hacer un análisis para un país determinado con información para un período largo de tiempo y sus series ya han sido ajustadas por el efecto de paridad del poder adquisitivo y variación en los precios. Adicionalmente, dicha fuente nos permite luego realizar un análisis para distintos países ya que tiene los mismos datos para una gran parte de la economía mundial. 
Figura 1

Apertura Económica en Perú

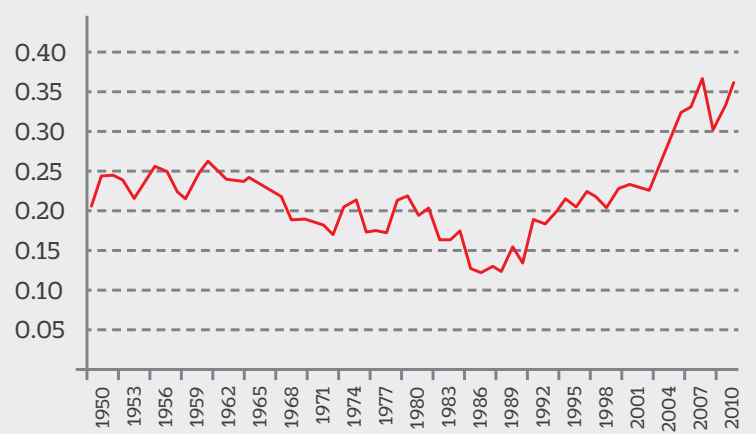

Como puede verse en la figura 1, el nivel de apertura económica del Perú ha ido creciendo a lo largo de los últimos 30 años. El país se ha comprometido institucionalmente con un proceso de apertura económica a través de la firma de una serie de tratados de libre comercio y convenios afines unilateral como multilateralmente. Ello ha permitido que los peruanos tengamos acceso a un número mayor de productos a precios económicos. Por otra parte, nuestros productos llegan a una cantidad importante de países sin pagar tarifas. Por lo tanto, la economía local se ha ido especializando en la producción de productos que son demandados por el mundo y en los cuales tenemos ventajas comparativas.

\section{¿ES BUENO EL COMERCIO INTERNACIONAL?}

En teoría sí es bueno, al menos eso nos diría Ricardo. Aunque es cierto que en el proceso de especialización, éste generará desempleo, malestar social y la necesidad laboral de nueva capacitación, toda vez que, como consecuencia de la mayor apertura, el trabajador desplazado tendría que capacitarse para recolocarse laboralmente en las industrias en las que el país decida especializarse. Pero es válido también preguntarse qué nos muestra la evidencia empírica y la experiencia internacional por ejemplo. Aquí también podemos utilizar los datos de la Penn World Table. El grafico 2 muestra el nivel de apertura económica para más de 150 países (en el eje Y), y el nivel de PBI per cápita (en el eje X) para el año 2011. Es decir, nos indicaría si existe algún tipo de relación entre el nivel de apertura económica y el producto per cápita de una economía.
Figura 2

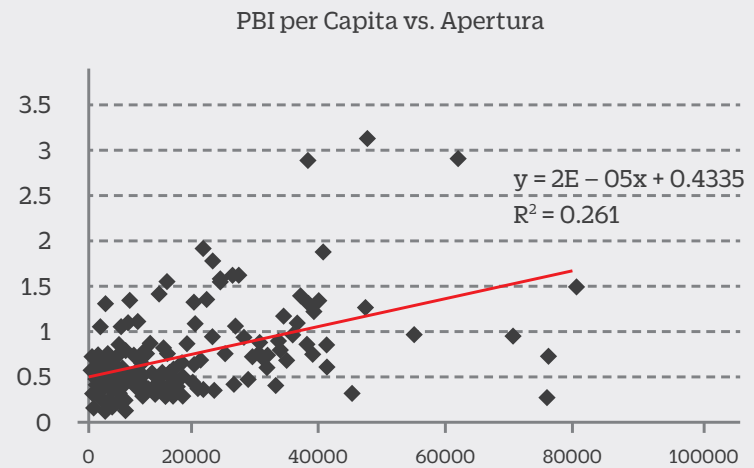

Como puede notarse, existe una relación de causalidad positiva entre las dos variables. Es decir, las economías con mayor apertura económica, logran un mayor nivel de producto per cápita y por lo tanto un mayor posibilidad de consumo per cápita. Podríamos decir entonces que Ricardo estaba en lo correcto. Es cierto, que el estadístico R-cuadrado, muchas veces utilizado como indicador de la fortaleza que tiene la relación encontrada, no es tan alto. Nuestro análisis es simple y del bajo valor que registra el coeficiente de determinación se desprende que otras variables, adicionales a la de apertura económica, explican la variación en el PBI per cápita. Sin embargo, ello no le resta relevancia a lo que hemos encontrado: el comercio internacional mejora los estándares de vida de la población.

NUESTRO ANÁLISIS ES SIMPLE Y DEL BAJO VALOR QUE REGISTRA EL COEFICIENTE DE DETERMINACIÓN SE DESPRENDE QUE OTRAS VARIABLES, ADICIONALES A LA DE APERTURA ECONÓMICA, EXPLICAN LA VARIACIÓN EN EL PBI PER CÁPITA. SIN EMBARGO, ELLO NO LE RESTA RELEVANCIA A LO QUE HEMOS ENCONTRADO: EL COMERCIO INTERNACIONAL MEJORA LOS ESTÁNDARES DE VIDA DE LA POBLACIÓN.

No cabe duda que hoy nos encontramos en una mejor situación que hace 20 años. La apertura económica que ha experimentado el Perú ha permitido que hoy tengamos, por ejemplo, acceso a tecnología de última 
generación y automóviles a precios accesibles. También ha dado origen a nuevas industrias localmente, que no existían anteriormente. Por ejemplo, hoy somos uno de los principales exportadores de quinua del mundo y nuestra oferta culinaria resalta sobre el resto.

\section{¿QUÉ NOS FALTA HACIA ADELANTE?}

Lo más importante es hacer un detallado análisis sobre los productos en los cuales Perú podría tener una ventaja comparativa. Es decir, productos que podríamos producir mejor que el resto. jTremenda tarea! Ello significa, por ejemplo, evaluar nuestra geografía, extensión de tierra, recursos humanos, acceso al capital y tecnología por citar algunos pocos aspectos relevantes.

Entonces, hay que seguir trabajando en dicha dirección y continuar fortaleciendo sectores donde tenemos ventajas comparativas. El sector forestal, por ejemplo, es uno que nos debería llamar la atención. No me cabe duda que podríamos ser una potencia mundial en la industria maderera. Algo así ha logrado Chile con menores condiciones que las peruanas en términos de terreno, biodiversidad y clima. Empresas como MASISA y ARAUCO son marcas mundialmente reconocidas y son empresas chilenas que han salido al mundo de la mano de la industria maderera. Y como este, estoy seguro que hay varios sectores en los cuales el Perú tiene ventajas comparativas.

\section{¿DEBEMOS SOLO CONCENTRARNOS EN LA APERTURA ECONÓMICA?}

La apertura económica es uno de los aspectos económicos importantes para lograr un crecimiento sostenido. Pero como este, hay muchas otras variables que afectan las posibilidades de crecimiento; la inversión pública y privada, por citar dos ejemplos. Lo cierto es que en el proceso de especialización hay ganadores y perdedores. Ciertamente los consumidores son los grandes ganadores cuando aumenta el comercio, ya que se amplían las posibilidades de consumo y a precios más bajos. Por el lado de los productores, hay tanto ganadores como perdedores. Ganan aquellos productores que ya vienen trabajando en industrias en las cuales Peru tiene una ventaja comparativa, ya que en el proceso de especialización ya tienen años de inversión en la industria. Pero también hay perdedores, y son aquellos productores que se dedican a producir bienes en los cuales Peru no tiene una ventaja comparativa. Una vez iniciado el proceso de especialización probablemente vayan saliendo del mercado y deban reasignar sus recursos en otras actividades.
La teoría económica nos dice que las ganancias del comercio superan ampliamente a sus pérdidas. Por lo tanto, el comercio es bueno, en la medida que se busquen mecanismos de transición ordenados. Aquí el rol del Estado es fundamental. Tanto a la hora de informar los planes nacionales estratégicos y de largo plazo que tiene respecto de la apertura económica. Si todos tenemos información respecto de los próximos tratados de libre comercio, por ejemplo, podemos anticiparnos y planificar que productos le venderemos al mundo y también cuales serán nuestros competidores. Asimismo, el Estado puede asistir en los procesos de reconversión y ajuste, por ejemplo, orientando a las industrias y promoviendo la reconversión e inversión en ciertos sectores. Definitivamente conviene continuar con el proceso de apertura económica. Desafíos hay muchos, pero las oportunidades son aún mayores. Como dice el dicho: "lo mejor está por venir".

\section{LA TEORÍA ECONÓMICA NOS DICE QUE LAS GANANCIAS DEL COMERCIO SUPERAN AMPLIAMENTE A SUS PÉRDIDAS. POR LO TANTO, EL COMERCIO ES BUENO, EN LA MEDIDA QUE SE BUSQUEN MECANISMOS DE TRANSICIÓN ORDENADOS. AQUÍ EL ROL DEL ESTADO ES FUNDAMENTAL..}

\section{REFERENCIAS}

Feenstra, R. C., Inklaar, R. \& Timmer, M.P. (2015). The Next Generation of the Penn World Table. American Economic Review, 105(10), 3150-3182.

Ricardo, D. (1817). On the Principles of Political Economy and Taxation. Londres: John Murray. 